\title{
Preventive Effect of L-Carnitine on the Disorder of Lipid Metabolism and Circadian Clock of Mice Subjected to Chronic Jet-Lag
}

\author{
Xiaoxian XIE ${ }^{* 1}$, Anqi GUO ${ }^{* 1}$, Tao WU ${ }^{1}$, Qinglian HU ${ }^{1}$, Liangfeng HUANG ${ }^{1}$, Cencen YAO ${ }^{1}$, \\ Binggong ZHAO ${ }^{1}$, Wanjing ZHANG ${ }^{1}$, Bingbing $\mathrm{CHI}^{1}$, Ping $\mathrm{LU}^{1}$, Zhenzhen $\mathrm{ZHAO}^{1}$, \\ Zhengwei FU ${ }^{1}$ \\ * These authors contributed equally to this work. \\ ${ }^{1}$ College of Biotechnology and Bioengineering, Zhejiang University of Technology, Hangzhou, \\ China
}

Received October 31, 2016

Accepted March 31, 2017

On-line July 18, 2017

\section{Summary}

Circadian clock plays an essential role in orchestrating daily physiology, and its disruption can evoke metabolic diseases such as obesity. L-Carnitine can reduce blood lipid levels, and ameliorate fatty liver through regulating lipid metabolism. However, whether L-Carnitine administration may affect the disturbance of lipid metabolism and circadian rhythm of mice induced by prolonged circadian disruption is still unknown. Herein, we investigated the effects of L-Carnitine on conditions of circadian clock and lipid metabolism through a chronic jet-lag mice model which was developed by reversing $12 \mathrm{~h}$ light/12 $\mathrm{h}$ dark cycle every 4 days for a continuous 12 weeks. Results showed that L-Carnitine administration significantly decreased levels of serum glutamic-oxaloacetic transaminase (GOT) and triglycerides (TG), which were remarkably elevated by chronic jet-lag. More importantly, quantitative real-time polymerase chain reaction (qRT-PCR) analysis indicated that L-Carnitine supplementation would effectively counteract the negative alterations in gene expression which related to lipid metabolism (Srebp1, Acaca, Fasn, and Scd1), metabolic regulator (mTOR) and circadian rhythm (Bmal1, Per1, Cry1 and Dec1) in the liver of mice subjected to the chronic jet-lag. As a conclusion, L-Carnitine was partly effective in preventing the disruption of circadian clock and lipid metabolic disorders induced by the chronic jet-lag.

\section{Key words}

Chronic jet-lag • Circadian clock • L-Carnitine • Lipid metabolism - Mice

\section{Corresponding author}

Z. Fu, College of Biotechnology and Bioengineering, Zhejiang University of Technology, No. 6 District, Zhaohui, Hangzhou, Zhejiang, 310032, China. Fax: 86-571-8832-0599. E-mail: azwfu@zjut.edu.cn

\section{Introduction}

The approximately $24 \mathrm{~h}$ light-dark (LD) cycle drives cyclic changes in the living environments for most organisms on earth from cyanobacteria to human beings. The mammalian circadian clock is composed of a master pacemaker and peripheral oscillators and takes an essential role in orchestrating daily physiology, including sleep/wake, body temperature, feeding, hormone secretion, and metabolism. Systemic circadian regulation is accomplished by the central oscillator in the suprachiasmatic nucleus (SCN) of the anterior hypothalamus. While, the peripheral clocks present in most vital organs, such as heart, liver, adipose tissue, and muscle (Albrecht 2012, Partch et al. 2014, Rey and Reddy 2013, van Alphen and Allada 2014). The molecular mechanism for oscillation in SCN and peripheral tissues is generated by interlocked negative transcriptional/translational feedback loops (Brown et al. 2012, Dibner et al. 2010), which are formed by several core clock genes including Period (Per1, Per2, and Per3) and Cryptochrome (Cryl and Cry2) and modulated by CLOCK-BMAL1 proteins. Orphan nuclear receptors 
REV-ERB and ROR families are also reported as the feedback regulative targets of CLOCK-BMAL1 (Bugge et al. 2012, Kohsaka et al. 2007).

Circadian clocks in our bodies provide time cues for activities and the synchronization of the metabolic reactions (Green et al. 2008, Sahar and Sassone-Corsi 2012). Proper function of circadian clock is of great importance in regulating physiological process. Until now, several external stimuli, such as overtime work, night eating, sleep disruption, as well as frequent shift/jet-lag (Haus and Smolensky 2006, Leloup and Goldbeter 2013), and chronic shift in LD cycles have been reported to influence the function of circadian clock (Oike et al. 2015). Further, the disruption can lead to internal desynchronization between the master clock and other peripheral oscillators, and increase the risk of many diseases, including obesity and other metabolic syndromes (Marcheva et al. 2010, Sahar and SassoneCorsi 2009, Turek et al. 2005). Chronic jet-lag leads to the dysregulation of leptin in adipose and central leptin resistance in wild-type mice, resulting in a high and arrhythmic serum leptin level over a $24 \mathrm{~h}$ period (Kettner et al. 2015), which may be associated with an obvious increase in body weight and fat composition ( $\mathrm{Wu}$ et al. 2015). Chronic jet-lag also disrupts the endogenous adipose clock, and abolishes the circadian rhythm of BMAL1 binding to leptin and Per1 promoters (Kettner et al. 2015). These findings demonstrate that chronic jet-lag might be closely associated with lipid metabolism and endogenous adipose clock in mice.

As known, L-Carnitine is involved in long-chain fatty acids transporting from cytosol to the mitochondria matrix (Marcovina et al. 2013), which is required for facilitating lipid metabolism and reducing the storage of long-chain fatty acids in adipose. In our previous study, we found that L-Carnitine supplementation could prevent irregular feeding-induced lipid metabolism disorder $(\mathrm{Wu}$ et al. 2015). However, whether L-Carnitine may affect the disorder of circadian rhythm and lipid metabolism of mice subjected to prolonged circadian disruption is still not reported. In the present study, we developed an experimental chronic jet-lag mice model by reversing $12 \mathrm{~h}$ light/ $12 \mathrm{~h}$ dark cycle every 4 days for a continuous 12 weeks to investigate the effects of L-Carnitine on the lipid metabolism and circadian clock. The results demonstrated that L-Carnitine supplementation prevented the impairment of the serum markers, and effectively counteracted the negative alterations in the expression of lipid metabolic genes and clock genes in mice.

\section{Materials and Methods}

\section{Materials}

L-Carnitine (Aladdin Chemistry Co. Ltd, Shanghai, China) was mixed with normal commercial diet at $0.5 \%$ w/w (L-Carnitine containing diet). A feeding of this diet (12.5 mg L-Carnitine/mouse/day) was equivalent to a dosage of about $400 \mathrm{mg}$ of L-Carnitine per $\mathrm{kg}$ of mouse weight each day. To ensure each mouse could consume the entire $12.5 \mathrm{mg}$ of L-Carnitine every day, mice were fed with $1 \mathrm{~g}$ L-Carnitine containing diet (20\% of total food intake) at first $2 \mathrm{~h}$, and then fed with $80 \%$ of normal commercial diet after they had eaten up the L-Carnitine containing diet.

\section{Animals and experimental design}

Male C57BL/6 mice (6-weeks old) were used in this research. The mice were housed in temperaturecontrolled $\left(22 \pm 1^{\circ} \mathrm{C}\right)$ quarters on a LD cycle 12:12, and provided water ad libitum and food only in the dark period. The onset of light was defined as Zeitgeber time 0 (ZT0) and the onset of darkness at ZT12.

After 7 days of acclimatization, mice were randomly divided into three groups of control (Con), jet-lag (JL) and jet-lag+Carnitine $(\mathrm{JL}+\mathrm{C})$. The experimental design was shown in Figure S1. Mice of $\mathrm{JL}+\mathrm{C}$ group were fed with L-Carnitine containing diet, and other mice were fed with normal commercial diet ( $5.0 \mathrm{~g} / \mathrm{mouse} /$ day). In Con group, mice were kept under the normal $\mathrm{LD}$ condition. In $\mathrm{JL}$ and $\mathrm{JL}+\mathrm{C}$ groups, mice were subjected to a reversal of LD cycle every 4 days for a continuous 12 weeks. Then after fasting for $12 \mathrm{~h}$, the mice in all three groups were sacrificed at ZT0 and ZT12 under the LD cycle.

The tissues of all mice were collected, frozen immediately in liquid nitrogen, and kept at $-80^{\circ} \mathrm{C}$ for RNA extraction. Blood was also collected and centrifuged at $6,000 \mathrm{x}$ g for $5 \mathrm{~min}$ at $4{ }^{\circ} \mathrm{C}$, then stored at $-40{ }^{\circ} \mathrm{C}$. Every effort was made to minimize animal suffering and the number of mice required for each experiment. All experiments were performed according to institutional guidelines, and the study was approved by the Research Committee of Zhejiang University of Technology.

\section{Biochemical analysis}

Plasma levels of glutamic-pyruvic transaminase (GPT) and glutamic-oxaloacetic transaminase (GOT) 
were measured by auto-biochemical analysis system (Achtection c8000; Abbott, North Chicago, Illinois, USA). The levels of triglycerides (TG), total cholesterol (TC), and high-density lipoprotein cholesterol (HDL-C) were analyzed using commercial kits (Whitman Biotech, Nanjing, China).

\section{Quantitative real-time $P C R$}

The cDNA templates were isolated from the mouse livers as previously described (Xie et al. 2014). Quantitative real-time polymerase chain reaction (qRT-PCR) was performed on an Eppendorf MasterCycler ep RealPlex4 (Wesseling-Berzdorf, Germany), with the SYBR ExScript PCR Kit (TOYOBO, Tokyo, Japan). The primer sequences of the selected genes used in the present study were shown in Table S1. The relative expression levels were calculated by $2^{-\Delta \Delta C T}$ method according to the previous description (Schmittgen and Livak 2008, Wu et al. 2008). The results were normalized to the expression level of glyceraldehyde-3phosphate dehydrogenase (GAPDH).

\section{Western blotting}

The proteins were isolated from hepatic samples, and their concentrations were measured using BCA Protein Assay Kit (Beyotime Institute of Biotechnology, China). The lysate was mixed with $5 \times$ SDS sample buffer and boiled for $10 \mathrm{~min}$. Lysate samples were separated on $6 \%$ and $12 \%$ SDS-polyacrylamide gels, and transferred to a PVDF membrane. The blots were blocked with $5 \%$ milk blocking solution for $2 \mathrm{~h}$ at room temperature and then incubated overnight with antibodies against PER1 (1:1,000; Abcam, USA), mTOR (mammalian rapamycin), Phospho-mTOR (1:1,000; Cell Signaling Technology, USA), and $\beta$-actin $(1: 1,000$; Beyotime Institute of Biotechnology). HRP-conjugated anti-rabbit IgG antibody (1:1,000; Beyotime Institute of Biotechnology) was used as the secondary antibody. The blots were visualized by ECL Western Blotting Detection Reagents (Beyotime Institute of Biotechnology) and the images were performed by GEL imaging system (Bio-Rad, USA). The quantification of proteins was analyzed by the software Quantity One (Bio-Rad, USA).

\section{Data Analysis}

Data are presented as mean \pm SEM. The values for mRNA levels are presented as relative values in all experiments. Data were checked for normality and homogeneity of variance using the Kolmogorov-Smirnov one-sample test and Levene's tests, respectively, before conducting statistical comparison. As the assumptions were met, the data were subjected to one-way analysis of variance (ANOVA).

\section{Results}

Effect of L-Carnitine on serum markers of mice subjected to chronic jet-lag

To investigate the effects of L-Carnitine on serum markers, the activity levels of GPT, GOT, TG, TC and HDL-C at ZT12 were measured. As shown in Figure 1, the activity levels of serum GPT and GOT were significantly higher in the JL group (Table S2, $p<0.05$ ) compared to those in the Con group. However, when supplemented with L-Carnitine, the serum GPT and GOT activities were decreased as compared with those in the JL group, and they did not exhibit obvious differences (Table S2, $p>0.05$ ) to the Con group (Fig. 1A, B). Moreover, a higher serum TG and TG/HDL-C ratio in the JL group were observed compared to the Con group (Table S2, $p<0.05$ ) (Fig. $1 \mathrm{C}, \mathrm{E}$ ), whereas there were no differences in the concentrations of serum TC and TC/HDL-C ratio among three groups $(p>0.05$; Fig. 1D, F).

Effect of L-Carnitine on hepatic mRNA levels of genes involved in adipogenesis

To test the effects of L-Carnitine on the lipid metabolism in mice subjected to chronic jet-lag, the mRNA levels of peroxisome proliferator activated receptor $\gamma(P P A R \gamma)$, sterol regulatory element binding protein 1 (Srebp1), Acetyl-CoA carboxylase (Acaca), fatty acid synthase (Fasn), stearoyl-CoA desaturase 1 (Scd1) and 3-hydroxy-3-methyl-glutaryl coenzyme A reductase $(\mathrm{Hmgcr})$ in the liver at ZT12 were analyzed. Among them, the mRNA levels of Acaca, Fasn and Scd1 were significantly increased by the chronic jet-lag treatment as compared with respective ones of the control, which were reduced significantly (Table S3, $p<0.01)$ by the supplementation with L-Carnitine. In addition, the supplementation with L-Carnitine also dramatically decreased the Srebpl mRNA level (Table S3, $p<0.01$ ) compared with that of both the Con and JL groups (Fig. 2B-E). No significant change was observed in the mRNA levels of PPAR $\gamma$ and Hmgcr among the three groups at ZT12 (Table S3, $p>0.05$; Fig. 2A, F). 
A

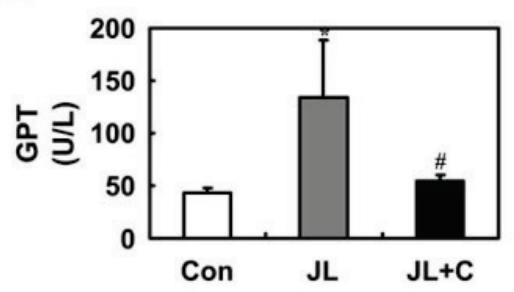

C

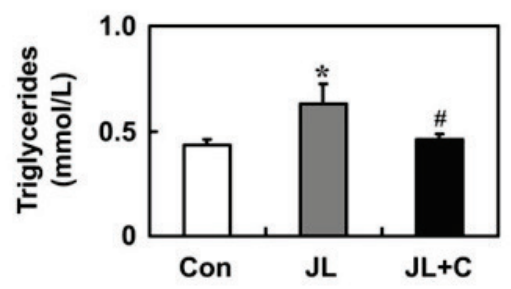

E

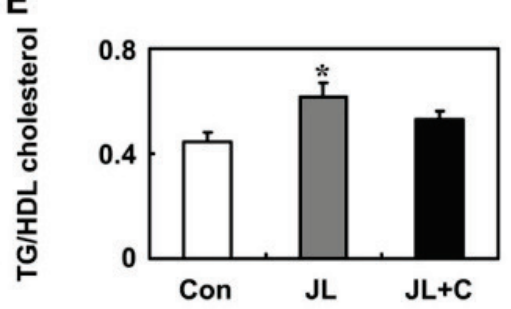

B

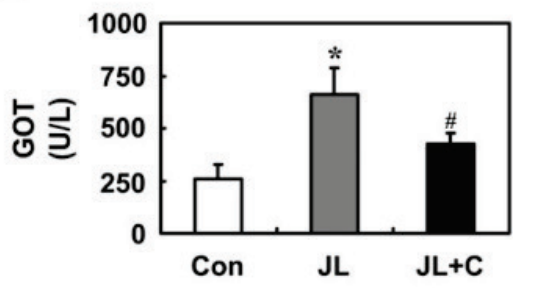

D

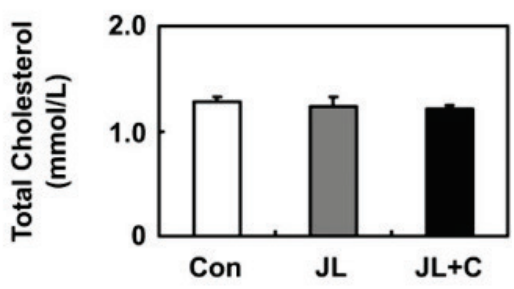

$\mathbf{F}$

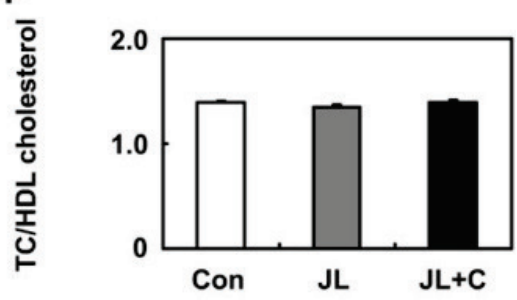

Fig. 1. Effect of L-Carnitine on serum parameters. After one week of acclimatization, mice were randomly divided into three groups of control (Con), jet-lag (JL) and jet-lag+Carnitine $(\mathrm{JL}+\mathrm{C})$. Mice of $\mathrm{JL}+\mathrm{C}$ group were fed with L-Carnitine containing diet, and other mice were fed with normal commercial diet $(5.0 \mathrm{~g} /$ mouse $/$ day $)$, during their active state (dark phase). In the Con group, mice were kept under LD conditions. In the $\mathrm{JL}$ and $\mathrm{JL}+\mathrm{C}$ groups, mice were subjected to a reversal of LD cycle every 4 days for a continuous 12 weeks. At the end of experiments, the serum concentration of GPT (A), GOT (B), TG (C), TC (D), TG/HDL-C (E) and TC/ HDL-C (F) were analyzed. Values are expressed as mean \pm SEM $(n=5)$. $* p<0.05$ compared with the control group; ${ }^{\#} p<0.05$ compared with the $\mathrm{JL}$ group. (A, B) liver enzymes (GPT, GOT): indicative of liver injury; (C-F) functional disturbance (TG, TC, TG/HDL-C, TC/HDL-C): compromised hepatic metabolism (adipogenesis).
A

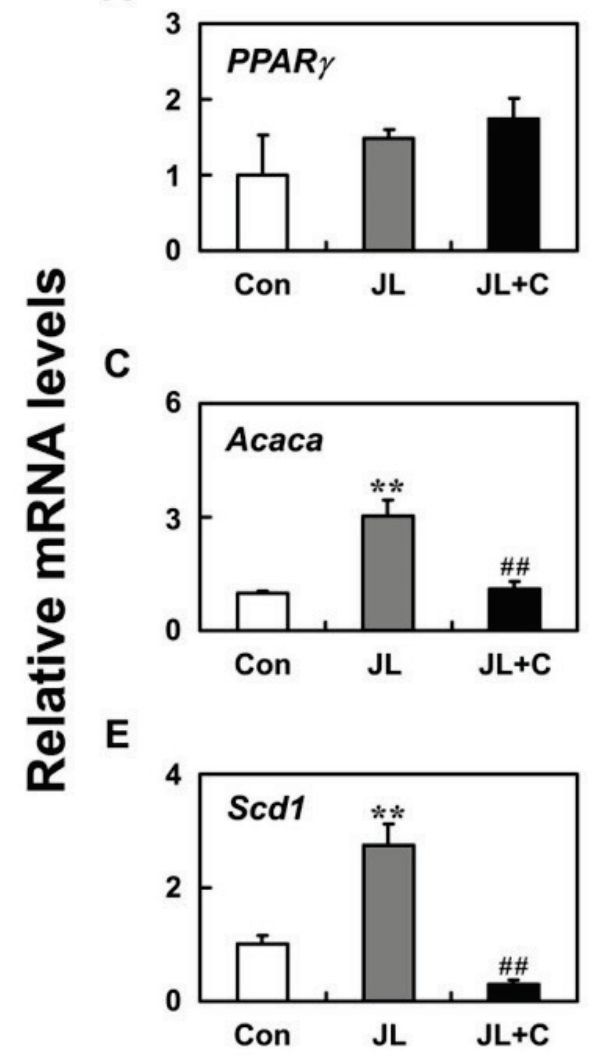

B

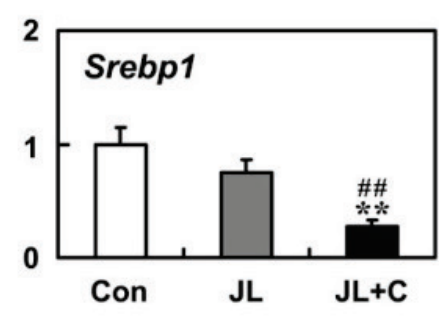

D

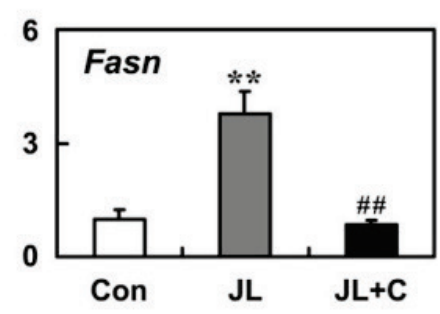

$\mathbf{F}$

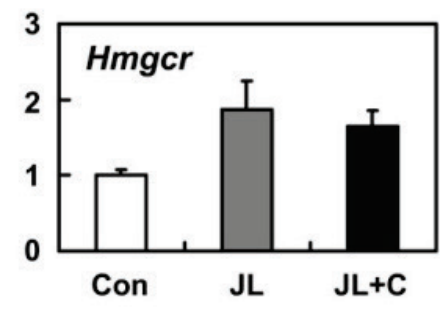

Fig. 2. Effect of L-Carnitine on hepatic mRNA levels of genes involved in adipogenesis. The mRNA levels of genes related to adipogenesis were determined by $\mathrm{qRT}$-PCR in the livers of Con, JL and $\mathrm{JL}+\mathrm{C}$ mice. The mRNA level was normalized using GAPDH. Each value represents the mean \pm SEM $(n=5)$. $* p<0.05$ compared with the control group; ${ }^{*} p<0.05$ compared with the $\mathrm{JL}$ group. 
Effect of L-Carnitine on the expression of lipolytic genes and glycometabolism-related genes (Gck and Pckl) in the liver

To explore the role of L-Carnitine supplementation in the expression of lipolytic genes, the mRNA levels of $P P A R \alpha$, carnitine palmitoyl transferase 1 (Cpt1), Cpt2, carnitine/acylcarnitine translocase (Slc25a20) in the liver at ZT12 were examined (Fig. 3).
The chronic jet-lag treatment increased the mRNA level of PPAR $\alpha$ and significant reduction in the mRNA levels of Cpt2 and Slc25a20 when compared with respective ones of the control, which were up-regulated partially (Fig. 3C) or completely (Fig. 3D) by the L-Carnitine supplementation, whereas, L-Carnitine supplementation had no effect on the expression of Cpt1 which was induced by the chronic jet-lag (Fig. 3A, B).
A

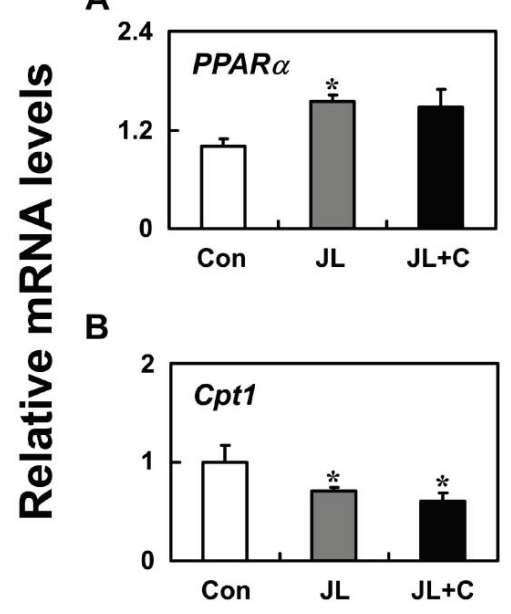

C

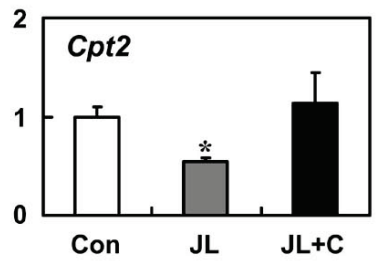

D

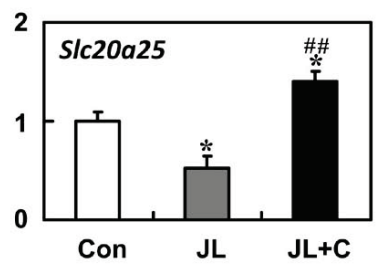

E

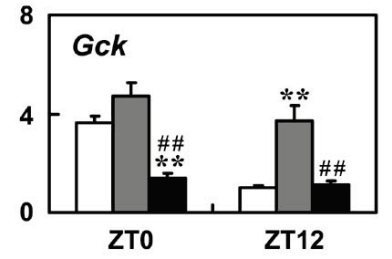

$\mathbf{F}$

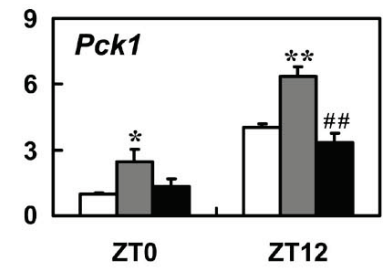

Fig. 3. Effect of L-Carnitine on hepatic mRNA levels of lipolytic genes and glycometabolism-related genes (Gck and Pck1).qRT-PCR was used to determine the mRNA levels of lipolytic genes and glycometabolism-related (Gck and Pck1) genes in the liver of Con, JL and $\mathrm{JL}+\mathrm{C}$ mice. The mRNA amount was normalized to the expression of GAPDH mRNA. Values are expressed as mean $\pm \operatorname{SEM}(n=5)$. ${ }^{*} p<0.05$ compared with the control group; ${ }^{*} p<0.05$ compared with the JL group. Values are expressed as mean $\pm \operatorname{SEM}(n=5)$.

Hepatic PPAR $\gamma$ is involved in provision of glycerol-3-phosphate (G3P) which is required for TG synthesis and storage (Nakamura et al. 2014). To investigate the effect of L-Carnitine on the PPAR $\gamma$ targeting genes, the mRNA levels of glucokinase $(G c k)$ and phosphoenolpyruvate carboxykinase 1 (Pckl) were measured (Fig. 3E, F). The chronic jet-lag treatment elevated the mRNA level of Gck at both ZT0 and ZT12, with a significant difference at ZT12 as compared with that of the control (Table S4, $p<0.01$ ). These increased changes were effectively lowered by L-Carnitine supplementation. Similar results were also observed for Pckl mRNA level. Briefly, the mice exhibited a significant up-regulation of $P c k 1$ expression (Table S4, $p<0.05$ ) in the JL group compared with those in the Con group at ZT0 and ZT12, while they exhibited a significant down-regulation of $P c k 1$ expression (Table S4, $p<0.01$ ) in the $\mathrm{JL}+\mathrm{C}$ group compared with those in the JL group at ZT12.

Effect of L-Carnitine on mTOR activity in the liver mTOR, a metabolic regulator, promotes light-evoked protein translation (e.g. PERIOD protein). It is also involved in lipid synthesis and energy metabolism (Cao et al. 2010, Laplante and Sabatini 2012). To investigate the effects of L-Carnitine on mTOR activity, mTOR mRNA level, total mTOR and phosphorylated mTOR (P-mTOR) protein levels were examined. As shown in Figure 4A, the mRNA level of mTOR in the JL group was significantly higher than that in the Con group at both ZT0 and ZT12 (Table S5, $p<0.05$ ), but was decreased by supplementation of L-Carnitine $(p<0.05)$. Protein level of mTOR was significantly lower in the $\mathrm{JL}+\mathrm{C}$ group as compared to that in the $\mathrm{JL}$ group at ZT12 (Table S5, $p<0.05$ ). However, P-mTOR protein levels were similar among the three groups at both ZT0 and ZT12 (Fig. 4B).

\section{Effect of L-Carnitine on hepatic mRNA and protein levels} of circadian clock genes

To test whether L-Carnitine plays a role in the regulation of circadian clock, we analyzed its effects on liver clock gene expression in mice subjected to a prolonged circadian disruption. As shown in the 
Figure 5A, the expression levels of circadian clock genes (Bmall, Perl, Cryl and Decl) were increased significantly (Table S6, $p<0.05$ ) in the JL group compared with those in the Con group at ZT0 and ZT12. L-Carnitine supplementation attenuated the impact on the expression of clock genes caused by the prolonged circadian disruption, and led to a significant decrease (Table S6, $p<0.05$ ) in their mRNA levels as compared to that of the JL group, except the expression of Perl at ZT0 (Table S6, $p>0.05$ ). Moreover, the protein level of PER1 was increased markedly (Table S6, $p<0.05$ ) in the JL group compared with that in the Con group at ZT0 and ZT12, which was decreased significantly (Table S6, $p<0.01)$ in the $\mathrm{JL}+\mathrm{C}$ group compared with that in the JL group (Fig. 5B).
A

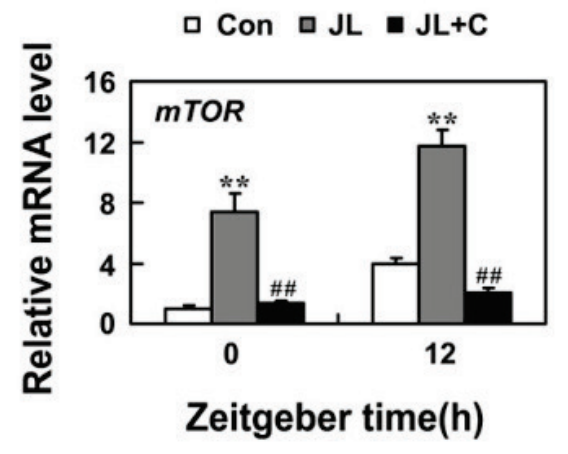

B

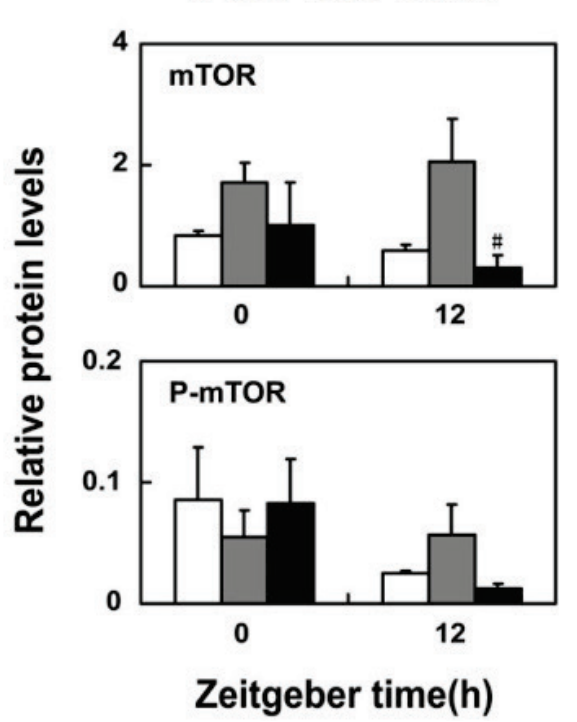

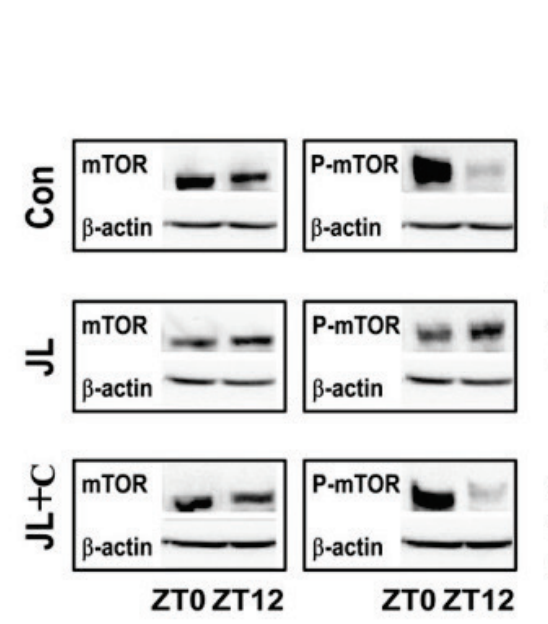

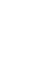

Fig. 4. Effect of L-Carnitine on mTOR activity. (A) qRT-PCR was performed to examine the mRNA level of $m T O R$ gene in the liver. The results were normalized to the expression level of the GAPDH gene. Each value represents the mean $\pm \operatorname{SEM}(n=5)$. (B) Western blot was performed to examine the protein levels of total mTOR and phosphorylated mTOR in the liver of Con, $\mathrm{JL}$ and $\mathrm{JL}+\mathrm{C}$ mice. $\beta$-actin was used for signal normalization. The protein content was quantified by densitometric analysis of blots. Each value represents the mean $\pm \operatorname{SEM}(n=3)$. 
A

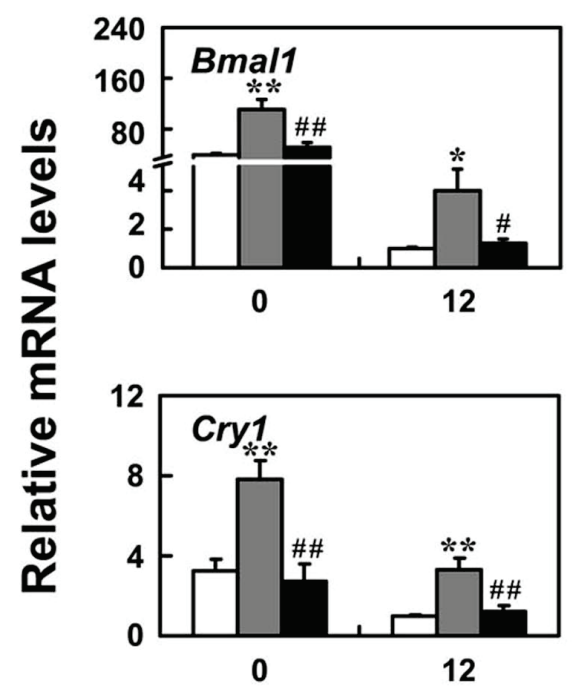

$\square$ Con $\square \mathrm{JL}=\mathrm{JL}+\mathrm{C}$
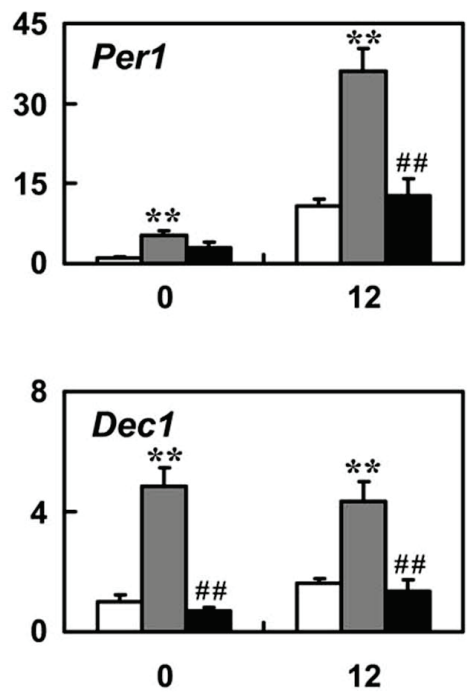

Fig. 5. Effect of L-Carnitine on circadian clock mRNA and protein levels. (A) The mRNA levels of clock genes were determined by qRT-PCR in the liver of Con, $\mathrm{JL}$ and $\mathrm{JL}+\mathrm{C}$ mice. The results were normalized to the expression level of the GAPDH gene. Values are expressed as mean \pm SEM $(\mathrm{n}=5) . * p<0.05$ compared with the control group; ${ }^{\#} p<0.05$ compared with the $\mathrm{JL}$ group. Values are expressed as mean \pm SEM $(n=5)$. (B) Western blot was performed to test PER1 expression in the liver of Con, $\mathrm{JL}$ and $\mathrm{JL}+\mathrm{C}$ mice. The PER1 protein content was quantified by densitometric analysis of blots. $\beta$-actin antibody served as loading control. Values are expressed the mean \pm SEM $(n=3)$.

\section{Zeitgeber time(h)}

B
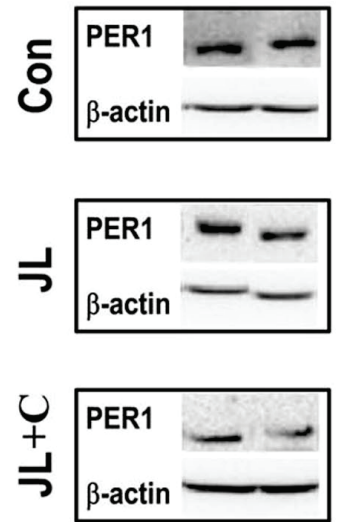

ZTO ZT12

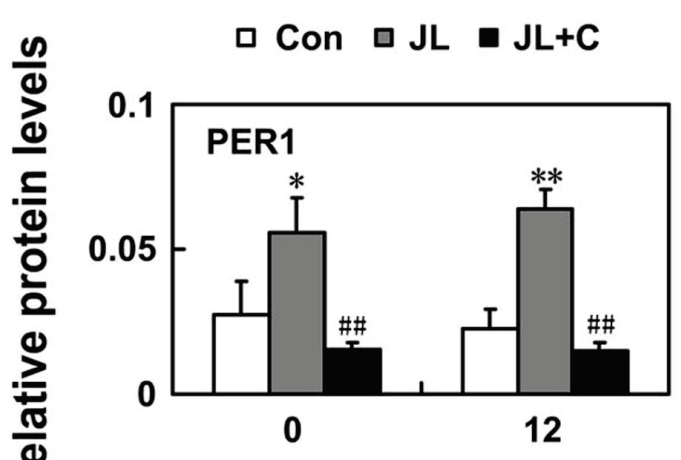

Zeitgeber time(h)
Our findings showed a significant disturbance in the lipid metabolism in mice subjected to the chronic jet-lag, being consistent with previous descriptions (Biggi et al. 2008, De Bacquer et al. 2009). The enhanced levels of hepatic enzymes of GPT and GOT by the chronic jet-lag could be indicative of liver injuries, possibly leading to hepatic maladaptation, which might be responsible for the increased serum levels of $\mathrm{TG}$ and TG/HDL cholesterol ratio. It is worth to point out that the supplementation of L-Carnitine could effectively prevent such lipid metabolism disturbance and liver injuries, suggesting that L-Carnitine might be used to protect the possible hepatic maladaptation from the frequent shiftworkers.

The significant up-regulated expression of lipogenic genes Acaca, Fasn and Scdl was produced by the chronic jet-lag, which was similar with the previous observations (Barclay et al. 2012). Such increased expression could be suppressed by L-Carnitine administration, suggesting L-Carnitine might be beneficial for hepatic steatosis, hyperlipidemia, and atherosclerosis (Li et al. 2011, Lima-Cabello et al. 2011). The expression of $\mathrm{Hmgcr}$, a susceptible gene responsible for cholesterol de novo biosynthesis, was not altered by exposing to the prolonged reversal of the photo-schedule, which was in line with the unaltered serum total cholesterol.

The carnitine palmitoyl transferase (CPT) system is mainly regulating fatty acid $\beta$-oxidation, and L-Carnitine transports long-chain fatty acid into the mitochondrial matrix (Priore et al. 2012). The frequent alteration of the photo-schedule had an impact on the expression of clock genes, and reduced mRNA levels of Cpt1, Cpt2, Slc25a20 in this system, suggesting that it 
might inhibit fatty acid oxidation, which was also observed by Li et al. (2014). However, the decreased mRNA levels of Cpt2 and Slc25a20 could be completely counteracted by L-Carnitine supplementation, demonstrating that supplementation of L-Carnitine was of benefit for long-chain fatty acids transporting into mitochondria, and thus might improve fatty acid metabolism in hepatic tissue (Longo et al. 2006).

Mice subjected to the chronic jet-lag exhibited significantly higher expression of Gck and Pckl genes, the proteins of which may contribute to the activation of PPAR $\gamma$ and the increase of the synthesis of TG via glycerol-3-phosphate (Nakamura et al. 2014). The increased expression of these two genes was reduced by L-Carnitine supplementation, suggesting that it might decrease TG level through inhibiting the expression of genes related with glycometabolism. In addition, the mTOR protein, a serine/threonine kinase, belongs to phosphoinositide 3-kinase (PI3K) related kinase family (Logan et al. 2012). It has been reported that the binding of insulin to the cell surface receptor activates PI3K, which positively up-regulates de novo lipogenesis by promoting glucose uptake, the expression of genes involved in lipid biosynthesis, and the deposition of excess carbohydrates to be stored as TG in hepatic tissue (Laplante and Sabatini 2009, Manning and Cantley 2007). These help explain our results that the increased TG synthesis was accompanied by the elevated expression of mTOR in the liver of mice. Thus, the decrease of mRNA and protein levels of mTOR by L-Carnitine administration, demonstrated that L-Carnitine attenuated the disruption of lipid metabolism of mice subjected to the chronic jet-lag, which was similar with the previous description (Kettner et al. 2015), through regulating mTOR pathways.

Mice subjected to the frequent shift of LD cycle exhibited significantly higher expression of hepatic clock genes (Bmall, Perl, Cryl and Decl), which are indirectly regulated by light as previously described
(Iwamoto et al. 2014, Reppert and Weaver 2002). Giving the close relationship of the PER protein expression with mTOR pathways, the PER1 and mTOR protein expressions were examined. The increased expression of both proteins by the chronic jet-lag supports the idea that light-evoked mTOR signaling may be required to augment PER protein expression (Cao and Obrietan 2010). Interestingly, increased protein levels of PER1 and the increased mRNA levels of Bmall, Perl, Cryl and Decl were clearly down-regulated by L-Carnitine containing diet, suggesting that L-Carnitine might play a positive role in the circadian adaptation, and might also be pivotal in stabilizing endogenous clock through evoking many pathways, such as mTOR. This hypothesis could be partially supported by accumulated studies on the essential role of circadian clock genes in interacting with several crucial metabolic factors for regulation of metabolic processes (Bugge et al. 2012, Cao and Obrietan 2010, Takeda et al. 2014).

In summary, the present study demonstrated that the exposure to the chronic jet-lag could lead to physiological maladaptation, the disturbance of hepatic lipid metabolism and circadian clock in mice. L-Carnitine supplementation could effectively counteract the negative alterations in the serum marker levels, and the expression of the genes regulating the lipid metabolism and hepatic clock rhythm. Our findings might provide the essential data toward elucidating the complicate relationship among L-Carnitine, lipid metabolism and hepatic circadian clock.

\section{Conflict of Interest}

There is no conflict of interest.

\section{Acknowledgements}

This work was supported by the National Natural Science Foundation of China (grant number 31200890), and the Scientific Innovation Program for University Students in Zhejiang Province (grant number 2014R403060).

\section{References}

ALBRECHT U: Timing to perfection: the biology of central and peripheral circadian clocks. Neuron 74: 246-260, 2012.

ASHER G, SASSONE-CORSI P: Time for food: the intimate interplay between nutrition, metabolism, and the circadian clock. Cell 161: 84-92, 2015.

BARCLAY JL, HUSSE J, BODE B, NAUJOKAT N, MEYER-KOVAC J, SCHMID SM, LEHNERT H, OSTER H: Circadian desynchrony promotes metabolic disruption in a mouse model of shiftwork. PloS One 7: e37150, 2012 . 
BIGGI N, CONSONNI D, GALLUZZO V, SOGLIANI M, COSTA G: Metabolic syndrome in permanent night workers. Chronobiol Int 25: 443-454, 2008.

BROWN SA, KOWALSKA E, DALLMANN R: (Re)inventing the circadian feedback loop. Dev Cell 22: 477-487, 2012.

BUGGE A, FENG D, EVERETT LJ, BRIGGS ER, MULLICAN SE, WANG F, JAGER J, LAZAR MA: Rev-erb $\alpha$ and Rev-erb $\beta$ coordinately protect the circadian clock and normal metabolic function. Gene Dev 26: 657-667, 2012.

CAO R, LI A, CHO HY, LEE B, OBRIETAN K: Mammalian target of rapamycin signaling modulates photic entrainment of the suprachiasmatic circadian clock. J Neurosci 30: 6302-6314, 2010.

CAO R, OBRIETAN K: mTOR signaling and entrainment of the mammalian circadian clock. Mol Cell Pharmacol 2: 125-130, 2010.

DAMIOLA F, LE MINH N, PREITNER N, KORNMANN BT, FLEURY-OLELA F, SCHIBLER U: Restricted feeding uncouples circadian oscillators in peripheral tissues from the central pacemaker in the suprachiasmatic nucleus. Gene Dev 14: 2950-2961, 2000.

DE BACQUER D, VAN RISSEGHEM M, CLAYS E, KITTEL F, DE BACKER G, BRAECKMAN L: Rotating shift work and the metabolic syndrome: a prospective study. Int J Epidemiol 38: 848-854, 2009.

DIBNER C, SCHIBLER U, ALBRECHT U: The mammalian circadian timing system: organization and coordination of central and peripheral clocks. Annu Rev Physiol 72: 517-549, 2010.

GREEN CB, TAKAHASHI JS, BASS J: The meter of metabolism. Cell 134: 728-742, 2008.

HAUS E, SMOLENSKY M: Biological clocks and shift work: circadian dysregulation and potential long-term effects. Cancer Cause Control 17: 489-500, 2006.

IWAMOTO A, KAWAI M, FURUSE M, YASUO S: Effects of chronic jet lag on the central and peripheral circadian clocks in CBA/N mice. Chronobiol Int 31: 189-198, 2014.

KETTNER NM, MAYO SA, HUA J, LEE C, MOORE DD, FU L: Circadian dysfunction induces leptin resistance in mice. Cell Metab 22: 448-459, 2015.

KIM YJ, KIM KY, KIM MS, LEE JH, LEE KP, PARK T: A mixture of the aqueous extract of Garcinia cambogia, soy peptide and L-carnitine reduces the accumulation of visceral fat mass in rats rendered obese by a high fat diet. Genes Nutr 2: 353-358, 2008.

KOHSAKA A, LAPOSKY AD, RAMSEY KM, ESTRADA C, JOSHU C, KOBAYASHI Y, TUREK FW, BASS J: High-fat diet disrupts behavioral and molecular circadian rhythms in mice. Cell Metab 6: 414-421, 2007.

LAPLANTE M, SABATINI DM: An emerging role of mTOR in lipid biosynthesis. Curr Biol 19: R1046-R1052, 2009.

LAPLANTE M, SABATINI DM: mTOR signaling in growth control and disease. Cell 149: 274-293, 2012.

LELOUP JC, GOLDBETER A: Critical phase shifts slow down circadian clock recovery: Implications for jet lag. $J$ Theor Biol 333: 47-57, 2013.

LI X, LI Y, YANG W, XIAO C, FU S, DENG Q, DING H, WANG Z, LIU G, LI X: SREBP-1c overexpression induces triglycerides accumulation through increasing lipid synthesis and decreasing lipid oxidation and VLDL assembly in bovine hepatocytes. J Steroid Biochem 143: 174-182, 2014.

LI Y, XU S, MIHAYLOVA MM, ZHENG B, HOU X, JIANG B, PARK O, LUO Z, LEFAI E, SHYY JY, ET AL.: AMPK phosphorylates and inhibits SREBP activity to attenuate hepatic steatosis and atherosclerosis in diet-induced insulin-resistant mice. Cell Metab 13: 376-388, 2011.

LIMA-CABELLO E, GARCÍA-MEDIAVILLA MV, MIQUILENA-COLINA ME, VARGAS-CASTRILLÓN J, LOZANO-RODRÍGUEZ T, FERNÁNDEZ-BERMEJO M, OLCOZ JL, GONZÁLEZ-GALLEGO J, GARCÍA-MONZÓN C, SÁNCHEZ-CAMPOS S: Enhanced expression of pro-inflammatory mediators and liver X-receptor-regulated lipogenic genes in non-alcoholic fatty liver disease and hepatitis C. Clin Sci 120: 239-250, 2011.

LIU L, ZHANG D, WANG M, FAN C, ZHOU F, WANG S, KONG L: The adverse effects of long-term 1-carnitine supplementation on liver and kidney function in rats. Hum Exp Toxicol 34: 1148-1161, 2015.

LOGAN RW, ZHANG C, MURUGAN S, O'CONNELL S, LEVITT D, ROSENWASSER AM, SARKAR DK: Chronic shift-lag alters the circadian clock of NK cells and promotes lung cancer growth in rats. J Immunol 188: 2583-2591, 2012. 
LONGO N, AMAT DI SAN FILIPPO C, PASQUALI M: Disorders of carnitine transport and the carnitine cycle. Am J Med Genet Part C Semin Med Genet 142C: 77-85, 2006.

MANNING BD, CANTLEY LC: AKT/PKB signaling: navigating downstream. Cell 129: 1261-1274, 2007.

MARCHEVA B, RAMSEY KM, BUHR ED, KOBAYASHI Y, SU H, KO CH, IVANOVA G, OMURA C, MO S, VITATERNA MH: Disruption of the clock components CLOCK and BMAL1 leads to hypoinsulinaemia and diabetes. Nature 466: 627-631, 2010.

MARCOVINA SM, SIRTORI C, PERACINO A, GHEORGHIADE M, BORUM P, REMUZZI G, ARDEHALI H: Translating the basic knowledge of mitochondrial functions to metabolic therapy: role of L-carnitine. Transl Res 161: 73-84, 2013.

NAKAMURA MT, YUDELL BE, LOOR JJ: Regulation of energy metabolism by long-chain fatty acids. Prog Lipid Res 53: 124-144, 2014.

OIKE H, SAKURAI M, IPPOUSHI K, KOBORI M: Time-fixed feeding prevents obesity induced by chronic advances of light/dark cycles in mouse models of jet-lag/shift work. Biochem Biophys Res Commun 465: 556-561, 2015.

PARTCH CL, GREEN CB, TAKAHASHI JS: Molecular architecture of the mammalian circadian clock. Trends Cell Biol 24: 90-99, 2014.

PRIORE P, STANCA E, GNONI GV, SICULELLA L: Dietary fat types differently modulate the activity and expression of mitochondrial carnitine/acylcarnitine translocase in rat liver. Biochim Biophys Acta 1821: 1341-1349, 2012.

REPPERT SM, WEAVER DR: Coordination of circadian timing in mammals. Nature 418: 935-941, 2002.

REY G, REDDY AB: Connecting cellular metabolism to circadian clocks. Trends Cell Biol 23: 234-241, 2013.

SAHAR S, SASSONE-CORSI P: Metabolism and cancer: the circadian clock connection. Nat Rev Cancer 9: 886-896, 2009.

SAHAR S, SASSONE-CORSI P: Regulation of metabolism: the circadian clock dictates the time. Trends Endocrin Met 23: 1-8, 2012.

SCHMITTGEN TD, LIVAK KJ: Analyzing real-time PCR data by the comparative C(T) method. Nat Protoc 3: 1101-1108, 2008.

TAKEDA Y, KANG HS, FREUDENBERG J, DEGRAFF LM, JOTHI R, JETTEN AM: Retinoic acid-related orphan receptor $\gamma(\operatorname{ROR} \gamma)$ : a novel participant in the diurnal regulation of hepatic gluconeogenesis and insulin sensitivity. PLoS Genet 10: e1004331, 2014.

TUREK FW, JOSHU C, KOHSAKA A, LIN E, IVANOVA G, MCDEARMON E, LAPOSKY A, LOSEE-OLSON S, EASTON A, JENSEN DR: Obesity and metabolic syndrome in circadian Clock mutant mice. Science 308: 1043-1045, 2005.

VAN ALPHEN B, ALLADA R: Knock, knock to reset the clock: mechanosensation and circadian rhythms. Cell Metab 19: 739-740, 2014.

WU T, GUO A, SHU Q, QI Y, KONG Y, SUN Z, SUN S, FU Z: L-Carnitine intake prevents irregular feeding-induced obesity and lipid metabolism disorder. Gene 554: 148-154, 2015.

WU T, JIN Y, NI Y, ZHANG D, KATO H, FU Z: Effects of light cues on re-entrainment of the food-dominated peripheral clocks in mammals. Gene 419: 27-34, 2008.

XIE X, MA Y, CHEN Z, LIAO R, ZHANG X, WANG Q, PAN Y: Transgenic mice expressing yeast CUP1 exhibit increased copper utilization from feeds. PloS One 9: e107810, 2014. 